\title{
Preschool Child Development in Egypt
}

\author{
Fatma AA. Hassan, PhD \\ Professor of Public Health \& Preventive Medicine, Community Medicine Department, Faculty of Medicine, Suez \\ Canal University, Egypt.
}

\begin{abstract}
This review describes the pattern and scope of the preschool child development, how to assess a child's development, to find out the factors affecting child's development and to describe the situation of children's development in Egypt. Preschool child is defined in this review as the child aged from $0-<6$ years. In Egypt, they represent $14.1 \%$ of the whole population, according to the last census 2006. Malnutrition among preschool children is still prevalent (29\% were stunted, $6 \%$ underweight; and $7 \%$ were wasted). Iron deficiency anemia is also prevalent among children and has implications on the normal development of the Egyptian preschoolers. Children in rural areas and Upper Egypt suffer more and need more attention. Rearing styles among the Egyptian families are those that not encouraging creative abilities and independence among the preschoolers. Poverty and illiteracy, especially among women will hinder the progress expected in the future with the advance knowledge and technology. These negative factors will be more prevalent in rural and upper Egypt. There is a need to conduct regular surveys on issues related to Egyptian preschool child development.
\end{abstract}

Keywords: Malnutrition, Rearing styles, Poverty.

\section{Introduction}

Children are the biggest promise for the nation's future. The family, community, and government are responsible for their survival, development, and protection. The Egyptian government took successful steps in saving children's life through promoting diarrheal disease control, vaccination and Integrated Management of Childhood IIInesses $(\mathrm{IMCl})^{(1)}$. It now focuses on child development programs aiming at developing a more physically and mentally productive new generation. The long term progress of any nation depends on how much it cares about its children ${ }^{(2-4)}$. The preschool age starts at birth For the first six years of a child's life represents a crucial period in his development. The Egyptian preschool children represented $14.1 \%$ of the whole population according to census $2006^{(5)}$. Giving care to understand what happens in this period of a child's life in Egypt will help in better planning for the future needs.

\section{Definitions}

\section{a. Preschool child:}

One of the adopted definitions of a preschool child is the one at age of $0-<6$ years ${ }^{(6,7)}$. Others restricted this age to the child aged $3-6$ years ${ }^{(8-11)}$. Pediatricians classified age from 0-3 years into two periods, i.e. Infancy from 0-1 year and toddler from 
$>1-3$ years. In this review, the preschool child is the one at age $0-<6$ years.

\section{b. Development:}

It is the process of maturation, differentiation, and acquiring skills that make the human being (in that case the child) adaptable to the environment ${ }^{(10)}$.

\section{c. Z score:}

Percent of reference median and/or standard deviation, i.e. How far the child deviates from accepted values ${ }^{(13)}$.

\section{d. Reference population:}

A population of apparently normal children whose measurements have been carefully collected, and analyzed to construct a scale. The current international growth reference is the National Center for Health Statistics (NCHS/World Health Organization Reference Population ${ }^{(13)}$. Using this reference population is based on the findings that well-nourished young children of all population groups follow a very similar growth pattern $^{(8,14,15)}$.

\section{e. Poverty:}

It is a level of income that is insufficient to ensure a minimum nutritional and basic consumption level to cover the costs of participating in the everyday life of the society $^{(16)}$.

\section{f. Developmental Quotient (DQ):}

It is a clinical estimate of maturity based on the overall picture and is a guide to the rate of developmental progress. $\mathrm{DQ}=$ =maturity age/ chro-nologic age $X 100^{(17)}$.

\section{g. Social Quotient (SQ):}

It is an estimate of social competence using the Vineland Social Maturity Scale ${ }^{(18)}$.

\section{Preschool Child Development}

There is an agreement among authors that child development is a continuous process of maturation, differentiation, and acquiring skills that make the child adaptable to the environment. It starts cephalocaudal i.e. The infant starts to control his neck first. The preschool child development includes the following: motor (gross and fine), speech, language, adaptive and personal social ${ }^{(10,17,19)}$. Physical growth is characterized to be rapid during infancy and a stable growth during childhood. Height velocity reaches its lowest point in childhood $^{(20)}$. In early infancy boys grow a little faster than girls and are taller than girls due to androgen's effect. Then at the age of 4 years, girls grow slightly faster than boys. Fetal hemoglobin is completely replaced by adult hemoglobin by 6 years of age. A study of 982 children aged 0-6 years in Asiut city to construct growth standards for preschoolers ${ }^{(8)}$. However, the details of sampling design were not described. Results showed the infantile component of growth velocity occurred early in infancy at the age of 0-6 month-interval. Results also showed two other growth velocities in childhood, one occurred early in childhood 2-3 year interval and the other occurred later at the age of 5.5-6 interval. Infants are characterized by self-centered behavior and immediate demands.

At the age of 2-6 years the child starts to explore his world and aware of others, i.e. He/she becomes a social being ${ }^{(10,19)}$. The detailed description of the developmental milestones across ages until 6 years is given in the pediatric textbooks. Regarding nutritional requirements, the infants need high calorie requirements. At the age of three the child need $90 \mathrm{kcal} / \mathrm{kg}$ per day from the four basic groups; milk, meat \& eggs, fruits \& vegetables and breads \& cereals. The child at the age of 5 years has a good appetite, but slow in eating. The child aged 6 years is very active and requests food. $\mathrm{He} / \mathrm{she}$ is a better starter than finishing the meal ${ }^{(19,20)}$. Children are ready to 
learn skills like self-help skills (toileting, dressing, eating by himself/herself) when they are mentally capable of understanding the usefulness of this skill and when they are physically capable of achieving it. Toileting as a skill needs more time and patience from the mother to teach her child as it is a more complicated skill than dressing to learn ${ }^{(12)}$. There are illustrated books that help mothers teach her preschool child. In Egypt among families of the middle class, toilet training started earlier than among lower class families. The median age of starting toilet training was found to be 7 months among the middle class and 10.5 months among the lower class families ${ }^{(21)}$. Continuous encouragement and more rewarding rather than punishment (used in $48 \%$ of study middle class families in (airo) were found to be successful facilitating approaches.

\section{Preschool child's needs to develop normally}

Preschool child needs could be classified into biological, psychological, moral, and educational needs ${ }^{(22)}$. In addition to nutritional needs to grow, many authors agree that love, play and to be treated as an individual and not as an object are among the basic requirements for the child to grow and develop well ${ }^{(10,11,16,17,21,23)}$. Attention, care, protection, empathy, understanding and social education for the roles and responsibilities would be what the child need for healthy development ${ }^{(11)}$.

In Egypt the economic conditions and a high population growth rate made it difficult to meet the child's needs for healthy development ${ }^{(21,24)}$. Currently child poverty is on the rise ${ }^{(25)}$. The decreasing amount of care and attention given to the child by his/her mother in Egyptian villages was emphasized $^{(26)}$.

\section{Factors affecting the preschool child development}

It is classified into intrinsic and extrinsic factors: Intrinsic factors, i.e. Genetic templates of the child. Height achievement through childhood is correlated with midparent height. Mother-child correlations of height and weight are slightly higher than father-child correlations. There is considerable height variation among parents and their offsprings but mid-parent height remains the most useful tool in describing the genetic relationship of growth between parents and children ${ }^{(19)}$. Extrinsic factors include, mother's health, fulfilling nutritional requirements, culture and traditions of the community that affect nutrition like breast feeding, weaning practices, family rearing styles, opportunities and chances given to the child to develop and the state of clean and safe environment in general. The risk factors associated with the nutritional status were the following; the mother's age, educational level and nutritional knowledge. In addition to whether the child was weaned on carbohydrates and whether vaccinated or not ${ }^{(27)}$. The following factors were associated with the child's development; prenatal care, maternal age at the index pregnancy, the mother's occupation, the level of the mother's education, the degree of consanguinity, the mother's obstetric history, father's occupation and educational level, the child's order, day care nursery, the child's condition at birth ${ }^{(10)}$. In 1984, the Ministry of Social Affairs and the Academy of Scientific Research studied 1440 preschool children from urban, rural, and desert areas. They found that $64.9 \%$ of the mothers and $72.7 \%$ of fathers did not have knowledge before marriage about how to rear their children. They also found that $51 \%$ of the fathers did not share in rearing their children ${ }^{(22)}$. 
The fathers' role with their children was not significant except in playing with them ${ }^{(29)}$. Obedience was the main value in child social up-bringing ${ }^{(16,29)}$. It is emphasized that the main aspect of a child's upbringing in the Arab culture was how he/she would be molded according to adult expectations either through domination or overprotection $^{(16)}$. This limits the child's freedom of thought, self-expression, and maturity ${ }^{(16,21)}$. It is clear that parents in Egypt Still persisted in adopting authoritarian patterns in rearing their children. This will hinder the development of child's creative abilities ${ }^{(16)}$. The work of the mother had an adverse effect on the child's development ${ }^{(31)}$. The most important thing was a happy, enthusiastic mother giving chances and opportunities to the child to develop $^{(17)}$. The biologically more mature infants i.e. In terms of birth weight and gestational age were more visually alert, less irritable, and less active. Girls were more visually alert than boys. The first-born infants showed increased activity levels compared with the second or later born infants ${ }^{(31)}$. The television has its pros and cons on the preschool children ${ }^{(11)}$. Parents are advised to watch TV with their children to explain and intervene.

\section{What we like to assess in a child's development?}

a. Physical development and growth, which its indicators are the nutritional status using height for age, weight for age and weight for height, arm circumference, and head circumference.

b. Social competence of the preschool child: It is assessed in these categories: general self-help, self-help in eating, self-help in dressing, self-direction, communication, locomotor, and socialization.

c. Mental and cognitive abilities.

\section{How to assess the preschool child development?}

Types of measurement: 1 . Cross-sectional data. 2. Longitudinal data. Longitudinal measurements tend to preserve and define the changes in growth in contrary to crosssectional data ${ }^{(9)}$.

A. Anthropometric measurements to assess physical development and growth:

The following indices ${ }^{(14,19,32-35)}$ are used to assess the nutritional status of the child: 1 ) Height-for-age to measure of past nutritional status, 2) Weight-for-height to measure of current nutritional status, 3) Weightfor-age, which is a composite indicator and does not distinguish between chronic and acute malnutrition, 4) Height-for-age by weight-for-height to identify who are both stunted and wasted. The indices of maturation in infancy are the size of the fontanelles and in the child development of the teeth ${ }^{(20)}$.

B. Developmental scales to assess psychsocial skills: The following are examples of developmental scales:

1) Denver Developmental Screening Test (DDST): It assesses developmental milestones up to age 6 years ${ }^{(10,20,36,37)}$. 2) Boyd Developmental Progress Scale: ${ }^{(18)}$ It is an easily administered scale. It tests behavior in three areas of motor, communication, and self-sufficiency skills from birth to 7 years. It focuses on the adaptive aspects of behavior in each of the three areas. It is useful in rehabilitation planning and training. Boyd Scale was modified to be used with Egyptian children. 3) The Gesell Developmental Schedules $^{(18)}$ : They are probably the most famous of the developmental scales. They cover the age range from 4 weeks to 6 years. No score or overall value is computed. It compares the developmental level of the child with normative data. 
They assess like DDST the four major areas of behavior; motor, language, adaptive and personal-social. 4) The Vineland Social Maturity Scale ${ }^{(18)}$ : It assesses development from birth to the age of 25 and over the years. It assesses the social-adaptive behavior of normal infants, children and adults. It is in a checklist format. Its items are arranged in order of difficulty by age levels. Its focus is on personal responsibility and independence. It yields a social age score from which a social quotient can be derived. 5) A composite scale derived from the mentioned scales and modified to suit the Egyptian culture ${ }^{(9)}$. Items derived from DDST, Boyd Developmental Progress Scale, and Gesell Development Schedules were used. It was tested and validated via a pilot study. However, the results of the pilot test were not included in her thesis. It was difficult to judge the quality of the composite tool. 6) Portage Guide to Early Education: It covers five areas; motor, socialization, cognition, self-help and language. It is used to assess and train the preschool children from birth to 6 years old both in the kindergarten and the home settings ${ }^{(38)}$.

\section{Assessment of mental abilities ${ }^{(38)}$ :}

1. Good enough to draw a man to assess IQ for the preschool children, 2. Wechsler Preschool \& Primary Scale of Intelligence (WPPI). 3. The Stanford Binet Intelligence Scale. 4. Z.A. intelligence scale for preschool children was done ${ }^{(38)}$. The items were tested on a small number of children.

\section{The situation of the Egyptian pre- school children}

1. The anthropometric measurements: The prevalence of low birth weight infants i.e. < $2.5 \mathrm{~kg}$ was $7 \%$ compared to $15 \%$ in Sudan ${ }^{(40)}$. This indicated the health of the mothers. The Egyptian national figures on low birth weight $(<2.5 \mathrm{~kg})$ were dated 1979 and 1983, at 14 and 7 percent of all births ${ }^{(41)}$. Data on the upper Egypt unfortunately were not available. Recommendation to fill the gap in data was given ${ }^{(41)}$. The nationwide surveys on the nutritional status of the Egyptian preschool as one of their objectives were different in their sample designs. Children under 5 years were surveyed ${ }^{(14,15}$, $34,35)$. Children aged 2-6 years were surveyed $^{(44)}$. The $Z$ score median in Aswan and Ismailia, -1.1 in Dakahlia and Cairo, and -2 in New Valley. Average weight-for age $Z$ scores were slightly positive ranged between -0.2 in Ismailia to -1 in New Valley. Weight-for-height $Z$ scores ranged from 0.0 in Aswan to 0.5 in Dakahlia. The prevalence of the stunted children aged 2-6 years was found in New Valley (56.8\%) and the lowest in Cairo (24.8\%). The prevalence of the underweight was $11.2 \%^{(44)} ; 10.4 \%^{(13)}$ and 9 percent ${ }^{(15)}$. This difference in prevalence of the underweight children could be due to different sample designs as in this survey under 2 years children were not included in the sample ${ }^{(44)}$. The percentage of stunted children aged 24-59 months in the period of 1980-1990 was 31 and the wasted children 1 percent ${ }^{(45)}$. Most recent estimates show that over $26 \%$ of children under the age of five are moderately or severely stunted ${ }^{(51)}$.

Results from a small study ${ }^{(46)}$ on nutritional status of 150 preschool children aged 2-5 years in Alexandria showed that $24 \%$ and $6.7 \%$ suffered from mild and moderate protein energy malnutrition respectively. Socioeconomic factors as well as the eating behavior of children affected the nutritional status. It is difficult to judge the quality of this study from the abstract. However, it is difficult to represent children from different socioeconomic levels with this small number of children. It could be possible later on to pool data of similar small studies and reanalyze the results. A prevalence of $22 \%$ of Protein Energy Malnutrition (PEM) among the preschool children was report- 
ed in the country paper on nutrition status in Egypt, 1991. This higher prevalence was attributed to vitamin A deficiency among preschoolers in spite of no clinical signs. Breast feeding among the infants under 12 months was common. However, the data were not analyzed according to the governorate to give more insight. Exclusive breast feeding among infants aged 4 months and less was increasing ${ }^{(15,47)}$. Among infants aged 4-6 months, $24 \%$ were exclusively breastfed ${ }^{(47)}$. A little higher percentage $(28.6 \%)$ was reported ${ }^{(48)}$. It could be due to the UNICEF's program for encouraging breast feeding. The percent of those under12 months that were not currently breast-fed was $6.6 \%$ out of 2353 surveyed infants. Bottle-fed infants under 12 months were $15.8 \%$ out of 2353 surveyed in $1995^{(47)}$. In 1994 it was reported that $67 \%$ of the infants from 0-1 year and 30\% of the under 2 and less than 10\% after the second year of life. The mean duration of breast feeding is 18 months ${ }^{(16)}$.

It was found to be for a longer period in rural areas; 19.7 months ${ }^{(15)}$. Through a longitudinal study assessed the nutritional status of 37 females and 23 males exclusively breast fed infants after delivery to the age of 6 months, the infants were allocated from 7 rural Maternal-Child Health $(\mathrm{MCH})$ care centers ${ }^{(49)}$. Results showed among infants aged 4-6 months, the highest prevalence of malnutrition as assessed by arm circumference for age (35.9\%). It was concluded that malnutrition was found among the exclusively breastfed infants under 6 months due to the low quality of the breast milk $^{(49)}$. This longitudinal study took a very small sample size. In addition, there was no control group of non-exclusively breastfed infants. Assessing the quality of the breast milk was needed to accept it as an explanation of the results. Through a communitybased study on diarrhea among 607 children aged 0-4 years in Atreess village, Giza results showed that all infants until 18 months of age who suffered from diarrhea were breast-fed. This finding was explained by the early introduction of additional supplements to breast milk ${ }^{(7)}$. Trends in child nutrition coincide with significant changes in the Egyptian economy and food subsidy policies between 1995 and 2005(51). The trends of nutritional status among Egyptian children under 5 years showed changes in different successive surveys ${ }^{(33-35)}$. Weight for age (wasting), height for age (stunting) and weight for length/ height (underweight) prevalence declined between 1995 and 2000, yet all show an increase between 2000 and 2005. These trends in increased child under-nutrition parallel increases in childhood obesity between 1995 and 2000 and declines in childhood obesity between 2000 and $2005^{(33-35,51)}$. In all three survey years, the bulk of the stunting is found among the one to four year olds. While the overall prevalence of stunting declined by over 30 percent between 1995 and 2000, the prevalence increased by $11 \%$ between 2000 , and 2005 in urban governorates ${ }^{(52)}$. The largest declines between 1995 and 2000 were found among female children between the ages of 2 and 4 years, who resided in the frontier governorates ${ }^{(33,52)}$. An increase in prevalence of undernutrition is expected to happen in the near future, especially in the marginal sectors like street children. Poverty is in rise ${ }^{(4)}$.

2. Iron deficiency anemia (IDA) among preschool children: The prevalence of iron deficiency anemia ranged between 20-25\% among the Egyptian preschool children ${ }^{(40)}$. This was a low prevalence compared to what was reported based on national survey 1978; $(38.4 \%)^{(42)}$ or $38 \%$ in 1996 and $2000^{(3,32)}$. The prevalence of anemia (HB < $11 \mathrm{gm} \%)$ was highest at 12-23 months (59.4\%) and gradually diminished till $12.8 \%$ at $60-71$ months $^{(42)}$. Anemia (HB $<11 \mathrm{gm} \%$ ) 
and severe anemia ( $\mathrm{HB}<9.5 \mathrm{gm} \%$ ) were more prevalent in rural areas in lower and upper Egypt The consequences of iron deficiency anemia include retarded psychomotor development, impaired cognitive function and growth retardation ${ }^{(50)}$. The significant increase in the prevalence of child stunting between 2000 and 2005 was accompanied by a $67 \%$ increase in the prevalence of childhood anemia, pointing to an overall deterioration in the nutritional status of Egyptian children under the age of five ${ }^{(51)}$. Among children under the age of five, the prevalence of anemia, increased from $31.9 \%$ in 2000 to over $50 \%$ in $2005^{(52)}$.

3. Vitamin A deficiency: Reliable information based on eye signs in preschool age children revealed only 4 cases out of almost 10000 sample children were found to have Bitot spots ${ }^{(16)}$. However, a history of night blindness was encountered among $0.4 \%$ of 6575 sample children who were 24 months or older ${ }^{(16)}$. Another survey showed the prevalence of vitamin A deficiency among preschool children was 11.9 percent $^{(3)}$. Updating data via regular surveys and increase the awareness about this problem is a successful strategy.

4. Rickets: Among preschool children aged 13-72 months in Cairo, rural and urban Minia; $2.6 \%$ out of 116 children in urban Minia, $0.8 \%$ out of 117 in Cairo and 0,4 out of 33 in rural Minia had rickets ${ }^{(52)}$.

\section{Conclusions}

Malnutrition is still a problem among preschool children. The prevalence rates were higher in rural areas, especially in Upper Egypt. Iron deficiency anemia is currently a common health problem. Poor illiterate mothers make the home environment not suitable for the child's development. Continuity of the current styles in child rearing will hinder the development of the child with creative abilities and independent styles. Breast feeding was common and continued on average for 18 months.

\section{References}

1. Rakha MA, Abdelmoneim AN, Farhoud S, Pièche $S$, Cousens $S$, Daelmans B, Bahl R. Does Implementation of $I M C l$ strategy have an impact on child mortality? A retrospective analysis of routine data from Egypt. BMJ.2013; 3 (1): 1-9.

2. Mahmoud Fathallah. Look on the Arab Child Health. Arab Child magazine. 1990, the first issue: 22-26.

3. United Nation Children's Fund (UNICEF). The State of the World's Children. Oxford University Press for UNICEF. 1996: 69-89.

4. United Nation Children's Fund (UNICEF). Child Rights report. 2012. Available on http://www. unicef.org.uk/.

5. The Central Agency for Public Mobilization \& Statistics (CAPMAS): Statistical Year Book. 2006.

6. El-Shebini S, Tapozada ST, Hanna LM, Gabriel GN. Nutritional status of infants and preschool children in a rural area in upper Egypt. The Egyptian Journal of Community Medicine. 1992; 10 (2): 47-57.

7. Tapozada ST, El-Shebini SM, Hanna LM, Metwalli OM, Galal OM, Gabriel GN. Socio-economic status and feeding practices associated with diarrhea in preschool children in upper Egypt. Egy J of Community Med. 1992; 10 (2): 59-70.

8. Darwish, O, Eid, EE, Fahmi, SI, Kamel, N. Standard anthropometric measurements for children attending day care centers in Alexandria. Bulletin of the High Institute of Public Health of Alexandria. 1978; 8 (2): 167-192. Alexandria University Press. 1979.

9. Hassan SAS, Gaber MAM, Ahmed ATG. Quantitative studies of body weight, length, weight and length velocities of Assiut infants and preschool children. 
Assiut Medical Journal. 1990; 14 (4): 289-301.

10. El-Sharkawy SG. Study of neurodevelopmental milestones of Egyptian Infants and children from birth to 3 years. Doctorate thesis. Faculty of Medicine/Suez Canal University. 1995.

11. United Nations Children's Fund (UNICEF). Helping the Young Traumatized Child: A Manual for Health and Community Workers and Preschool Teachers. UNICEF MENA Regional Office. Aman, Jordan. 1995.

12. Rubin RR, Fisher JJ. Your preschooler: A Johnson \& Johnson Child Development Publications. 1982.

13. World Health Organization (WHO): Training Modules for Household Surveys on Health and Nutrition. 1988: 132136.

14. Abdel Azeem F, Fasid SM, Khalifa AM. Egypt Maternal and Child Health Survey 1991. Pan Arab Project for child development. Arab Republic of Egypt Central Agency for Public Mobilization and Statistics (CAPMAS). 1993: 275-338.

15. El-Zanaty FH, Egypt Demographic and Health Survey (DHS) 1992. National Population Council, Demographic and Health Surveys Macro International Inc. November 1993: 149-158.

16. The Central Agency for Public Mobilization \& Statistics (CAPMAS) and the United Nations Children's Fund (UNICEF): The state of Egyptian children \& women. 1994: 26-30; 79-90.

17. Lowrey $\mathrm{GH}$. Growth and development of children. Yearbook Medical Publishers, Inc. Chicago, London. 1986: 48-49; 143-200.

18. Lezak MD. Neuropsychological Assessment. $2^{\text {nd }}$ Edition, Oxford University Press. 1983: 586-589.

19. Rallison MI. Normal Growth in Children. In Growth Disorders in Infants, Children, and Adolescents. A Wiley Medical Publication. 1986: 78-101.
20. Rallison MI. Standards of Normal Growth. In Growth Disorders in Infants, Children, and Adolescents. A Wiley Medical Publication. 1986: 144-175.

21. Farrag $O$. The Role of the Family in Socialization Process. In Child Development and Socialization Processes in Egypt: Materials on Childhood in Egypt (Part B). Hanss-Seidel-Stiftung. 1995.

22. Search childhood problems in the preschool stage The Ministry of Social Affairs with the Academy of Scientific Research and Technology,. 1984.

23. Hallouda AM, UNICEF program officers. National programs of Action (NPA) for Egypt. 1993: 4.4; 4.5.1.

24. Ahmed Hassan: the impact of population growth on the development of childhood and motherhood in the Third Five-Year Plan for Economic and Social Development 1992/1993-1996/1997. Volume II (background papers) -The National Council for Childhood and Motherhood. 1992: 1-38.

25. AkI Y. UNICEF social policy programs, strategic interventions to address child poverty in Egypt. 2012.

26. El-Saaty SH, Infant-Mother Relationship in the Egyptian Village: A cluster of traditional technologies: In the Image of the childhood in Egypt. Hanns-SeidelStiftung. 1995: 39-44.

27. El-Saadany AR, Risk $M$, Abu Naga N, Mahfouz M, Fawzi M, Marie M. Correlation between the type of feeding in early infancy and intelligence in preschool children. Benha Med J. 1985; 2 (1): 47-51.

28. Abd El-Rahaman, HA, Mohamed, T, Shoulah, AS, Moslamani, AM. Beliefs and traditional practices affecting nutritional status in infancy at Kaliobia governorate. The Egyptian Journal of Community Medicine. 1994; 12 (2): 8187.

29. Khattab M, Abd El-Baky F, Abdel Wahab A, Gharabwy LA, El-Defrawi H. 
The Impacto f Rearing Style on Psychosocial Development of Children in PortFouad. The Egyptian Journal of Psychiatry. 1994; 17: 67-75.

30. Ibrahim N, Kamel LM, Brrigham C, Risk SM, Fouad NA. Relationship between environmental stimulating activities and the psychosocial development of children in the first three years of life in a rural community. Medical Journal of Cairo University. 1996; 64 (3) (Suppl.): 111-118.

31. Bishry, Z, Salem, SI, Yunis, FA, Monir, $Z M N$, Khalifa, AG. Behavioral correlates of the nutritional status of the newly born infants. Medical Journal of Cairo University. 1996; 64 (1) (Suppl,): 289303.

32. Moore WM. Pediatric Anthropometry. Ross Laboratories. 1987: 5-15.

33. El-Zanaty F, Ann Way. Egypt Demographic and Health Survey 2000. Cairo. Egypt. Ministry of Health and Population, National Population Council, El-Zanaty and Associates, and ORC Macro. January 2001: 171-175.

34. El-Zanaty F, Ann Way. Egypt Demographic and Health Survey (EDHS) 2005. Cairo. Egypt. Ministry of Health and Population, National Population Council, El-Zanaty and Associates, and ORC Macro. February 2006: 169-180.

35. El-Zanaty F, Ann Way Egypt Demographic and Health Survey 2008. Cairo. Egypt. Ministry of Health and Population, National Population Council, El-Zanaty and Assoc-iates, and ORC Macro. March 2009: 183-188.

36. Kamel LM, Labib NA, El-Salamony OK. Assessment of Denver's developmental screening test as a tool for developmental screening among a group of children aged 1-3 years. JAC. 1990; 1 (1): 53-60.

37. Abu-Elmagd, AA, Hassanein, FE, Ibrahim, SAM, Mohey Eldin, Z. Denver Developmental Screening Test (DDST) of preschool children in Assuit city. Assuit Med J. 1992; 16 (5): 95-102.

38. Palestinian Red Crescent Society. The right to life. Carretas, Oxfam: Portage Educational Program Early, Arabized Edition pilot. Arabization project and use the manual Portage Educational Early

39. Zakaria Ahmed El Sherbini, Abdul Latif Junkie: A test uniforms to the intelligence of children in pre-school stage. Psychological studies. 1993: 289320.

40. Mahmoud Abbas Khodeir, Samir Salim $A D$. The reality of the child in the Arab world. Arab Council for Childhood 1989.

41. Allen, LF. The situation of children in upper Egypt. The central Agency for Public Mobilization \& Statistics (CAPMAS) and the United Nations Children's Fund (UNICEF). 1989: 2-12, 34-43.

42. El-Deeb B, Hefny K, Hussein MA, Moharram S, Oldham L. The state of Egyptian children; The central Agency for Public Mobilization \& Statistics (CAPMAS) and the United Nations Children's Fund (UNICEF): 1988: 76-87.

43. Arab Republic of Egypt country paper: Nutrition status in Egypt, December, 1991. In preparation for International Conference of Nutrition. Rome, Dec, 1992. WHO/FAO. 1992.

44. National Agricultural Research Project (NARP). Development of food consumption monitoring system. Final report. Egypt, September, 1995.

45. World bank world development report: Investing in health: World development indicators. Oxford University Press. 1993: 75-80.

46. El-Talyawi MST. A study of the impact of some variables on the nutritional status of a sample o preschool children in Alexandria city. Communications in Sciences \& Development Research. 1992; 37: 1-17. (English Abstract).

47. El-Zanaty F. Egypt Demographic and Health Survey (EDHS). Preliminary re- 
port. National Population Council, Demographic and Health Surveys Macro International Inc. 1995.

48. UNICEF. Nations march: combat diseases of malnutrition among children, 1996.

49. Noor EF, Abd El-Maksoud AM, Abd ElGalil AA. Exclusive breast feeding and nutritional status of infants. Medical Journal of Cairo University. 1996; 64 (3) (Suppl.): 103-109.

50. Black RE. Micronutrient deficiency-an underlying cause of morbidity and mortality. Bull World Health Organ (WHO). 2003; 81: 79.

51. Austin A. Stunting Trends among Egyp- tian Children <5: 1995-2005 Child nutrition in the context of economic change and food subsidies . Harvard School of Public Health, Department of Population and International Health, Harvard School of Public Health, Huntington Avenue, Boston, MA 02115, USA 2009.

52. Abdel Fattah $M$, Hammam HM, Sadek $\mathrm{RR}$, et al. Comparative study of the nutrional status between preschool children of El-Minia and Cairo governorates El-Minia Medical Bulletin. 1991; 2 (3): 130-140. 